\title{
CONCEPÇÕES E ABORDAGENS DA AGRICULTURA FAMILIAR E DO AGRONEGÓCIO EM LIVROS DIDÁTICOS DE GEOGRAFIA
}

\author{
Jaqueline Niendicker de Lima ${ }^{1}$, Cecilia Hauresko ${ }^{2}$
}

\begin{abstract}
${ }^{1}$ Mestre em Geografia pela Universidade Estadual do Centro-Oeste - UNICENTRO, E-mail: jaquelineniendicker@gmail.com,Orcid: http://orcid.org/0000-0002-6169-1840

${ }^{2}$ Professora do Curso de Graduação e do Programa de Pós-graduação em Geografia da Universidade Estadual do Centro-Oeste - UNICENTRO, E-mail: chauresko@unicentro.br, Orcid: http://orcid.org/ 0000-0002-31982735
\end{abstract}

Artigo recebido em 07/02/2021 e aceito em 13/08/2021

\begin{abstract}
RESUMO
O trabalho apresenta resultados de pesquisa de mestrado, cujo objetivo foi analisar as abordagens teóricas da agricultura brasileira, especificamente a agricultura familiar e o agronegócio nos livros didáticos de Geografia para estudantes do $6^{\circ}$ e $7^{\circ}$ anos, Séries finais do Ensino Fundamental tomando como base os enfoques da Geografia Agrária sob a perspectiva crítica. A opção pelo estudo dos temas e suas abordagens no livro didático se deve à importância da atividade agrícola no Brasil, seus vários rurais, e do livro didático no processo de ensino-aprendizagem de Geografia. Foram estudadas três coleções: Expedições Geográficas, Vontade de Saber e Geografia Espaço e Vivência. Para tanto, além da literatura consultada, utilizou-se o método qualitativo de pesquisa, o qual trata principalmente dos aspectos da realidade que não podem ser quantificados. Para exploração, levantamento e análise do conteúdo, o trabalho apoia-se em Bardin (1977), mediante a Metodologia da Análise do Conteúdo. Não se observou nenhum equívoco conceitual, mas se entende que os temas em foco poderiam ser mais explorados pelos autores. Há predominância em duas coleções, de forma mais destacada, de uma geografia quantitativa e descritiva e, portanto, fica claro que, para reforçar a criticidade dos estudantes, caberá ao professor indagar e discutir os temas com eles, apoiando-se em outras fontes de informação, como defendido pelos pesquisadores e professores da educação geográfica.
\end{abstract}

Palavras-chave: Livros didáticos; Geografia; Análise; Agricultura.

\section{FAMILY AGRICULTURE AND AGRIBUSINESS: CONCEPTIONS AND APPROACHES IN GEOGRAPHY TEXTBOOKS}

\section{ABSTRACT}

The work presents part of the results of the master's research whose objective was to analyze the approaches and conceptions of Brazilian agriculture, especially family one and agribusiness in the Geography textbooks for students of the $6^{\text {th }}$ and $7^{\text {th }}$ years of Elementary School "Last Years" taking 
theoretical approaches of Agrarian Geography from a critical perspective as basis. The option to study the themes and their approaches in the textbook is due to the importance of the agricultural activity in Brazil, its various rural, and of the textbook in the teaching-learning Geography process. Three collections were studied: Expedições Geográficas, Vontade de Saber e Geografia Espaço e Vivência. Thereunto, qualitative research method was used, which deals mainly with unidentifiable aspects of reality. For exploration, survey, and content, the work is supported by Bardin (1977), through the Content Analysis Methodology. There was no conceptual mistake, but it is understood that the themes focused could be better explored by the authors. There is predominance in two collections more prominently, of a quantitative and descriptive geography, and therefore, it is clear that to reinforce the students criticality, the teacher will be up to ask them and discuss the themes with them, based on other sources of information, as advocated by researchers and teachers of geographic education.

Keywords: Textbooks. Geography. Analyze. Agriculture.

\title{
CONCEPCIONES Y ABORDAJES DE LA AGRICULTURA FAMILIAR Y DEL AGRONEGOCIO EN LIBROS DIDÁCTICOS DE GEOGRAFÍA
}

\begin{abstract}
RESUMEN
El trabajo presenta parte de resultados de una investigación de maestría, cuyo objetivo fue analizar los abordajes de la agricultura brasileña, específicamente la agricultura familiar y el agronegocio, en libros didácticos de Geografía para estudiantes de $\operatorname{los} 6^{\circ}$ y $7^{\circ}$ años de la Enseñanza Fundamental Años Finales", teniendo como base los abordajes teóricos de la Geografía Agraria bajo la perspectiva crítica. La opción de estudiar los temas y sus enfoques se debe a la importancia de la actividad agrícola en Brasil, sus varios rurales y de los libros didácticos en el proceso de enseñanza-aprendizaje de la Geografía. Fueron estudiadas tres colecciones: Expedições Geográficas, Vontade de Saber y Geografia Espaço e Vivência. Para ello, fue utilizado el método cualitativo de investigación, lo cual trata principalmente de los aspectos de la realidad que no se pueden cuantificar. Para explotación, recopilación y análisis del contenido, el trabajo se apoya en Bardin (1977), mediante la Metodología del Análisis de Contenido. No se observó ningún equivoco conceptual, pero se entiende que los temas en foco podrían ser más explotados por los autores. Hay predominancia en dos colecciones, de forma más destacada, de una geografía cuantitativa y descriptiva, y por lo tanto, se queda claro que, para reforzar la criticidad de los estudiantes, el profesor deberá indagarlos y discutir con ellos los temas, apoyándose en otras fuentes de información, como defendido por los investigadores y profesores de la educación geográfica.
\end{abstract}

Palabras clave: Libros didácticos. Geografía. Análisis. Agricultura.

\section{INTRODUÇÃO}

Neste artigo, apresentamos parte dos resultados de uma pesquisa de mestrado em Geografia que investigou as abordagens teóricas da agricultura familiar e do agronegócio em livros didáticos do Ensino Fundamental, Anos Finais, para as turmas do $6^{\circ}$ e $7^{\circ}$ anos, tomando como base os enfoques teóricos da geografia agrária sob a perspectiva crítica. A realização do estudo tem como foco a importância da atividade agrícola no Brasil, seus vários rurais, 
sobretudo o livro didático no processo de ensino-aprendizagem de Geografia. Especificamente, objetivou-se: a) levantar as temáticas que gravitavam em torno dos temas centrais; b) identificar que imagens e quais conteúdos relativos a essas duas temáticas são trabalhados com os estudantes; e c) verificar de que forma o material analisado pode contribuir para o desenvolvimento do pensamento crítico ${ }^{1}$ nos alunos.

A escolha das temáticas a investigadas ocorreu devido à construção de uma trajetória de estudos sobre o campo brasileiro em geral e a agricultura familiar, em particular e principalmente, porque a esta última e o agronegócio coexistem no espaço rural brasileiro de maneira que as diferenças entre essas duas formas de organização de produção no campo devem ser analisadas e entendidas continuamente, enquanto fatos que são construídos e modificados no tempo-espaço, e alguns mantidos. Por isso, voltar no passado coloca-se como necessário para compreender a formação territorial brasileira, as relações de produção, a predominância de características de um subsetor e de outro, e os fatores econômicos e sociais que as marcaram. Desde o período colonial, o Brasil já exercia o papel de produtor de commodities, destinando e priorizando a monocultura e a produção em grande escala que, por vezes, estigmatiza e inferioriza a produção familiar de camponeses, indígenas, quilombolas e demais populações tradicionais. Aproveita-se para esclarecer que o termo agricultura familiar nomeia muitas situações e sujeitos diferentes e, se compreendida genericamente, pode encobrir a diversidade cultural do rural brasileiro (ALVES, 2010).

\footnotetext{
${ }^{1}$ Para tratar do pensamento crítico, baseamo-nos em Freire (1987), que enfatiza a ideia da pedagogia como a prática da liberdade. $\mathrm{O}$ autor defendia que a conscientização crítica permitiria uma construção de conhecimento e aprendizagem alternativa à concepção bancária de educação, onde os alunos se enfileiram para receber a transferência e depósito de conhecimentos pelos professores, impedindo a construção do pensamento crítico. Também incorporamos Campos (2007), que define o pensamento crítico como um conjunto complexo de habilidades intelectuais que são usadas para fins específicos, incluindo as de analisar cuidadosa e logicamente a informação para determinar a validade, a veracidade de sua argumentação ou de suas premissas e a solução de um problema. Afirma-se, porém, que não há um consenso geral sobre o conceito de pensamento crítico. De acordo com Loïc Wacquant (2006, apud BALAGUER MORA, 2018), há duas abordagens principais que acreditamos serem complementares: 1. Uma acepção kantiana que "na linha do filósofo de Königsberg, significa o exame avaliativo de categorias e formas de conhecimento a fim de determinar sua validade e valor cognitivo" (BALAGUER MORA, 2018, p. 44). O caráter crítico desta primeira acepção coloca a ênfase na busca de conhecimento confiável e válido universalmente, que torna possível os resultados que podem ser aceitos pela comunidade científica em um sentido amplo. 2. Uma visão marxista que "aponta as armas da razão para a realidade sócio histórica [sic] e visa lançar luz sobre as formas ocultas de dominação e exploração que a moldam, a fim de revelar em termos negativos, as alternativas que obstruem e excluem" (BALAGUER MORA 2018, p. 44). Nesta segunda acepção, porém, a ênfase do termo crítico está, agora, em seu potencial transformador, na capacidade de oferecer alternativas para moldar um mundo melhor, livre de exploração e dominação.
} 
A atuação de diferentes atores classificou a agricultura brasileira em dois modelos de agricultura, o agronegócio e agricultura familiar e, diante desta forma dual de produção, é importante compreender suas abordagens nos livros didáticos, já que este material é, para muitos estudantes, o único, e por isso mesmo serve de guia orientador da maior parte das atividades no processo de ensinar e de aprender. Cabe ressaltar que não temos pretensão de criticar a abordagem utilizada pelos autores dos livros didáticos, mas compreender como a agricultura familiar e o agronegócio, também chamado de agricultura capitalista, agricultura patronal ou agricultura empresarial (FERNANDES; MOLINA, 2004b), são explorados. Para tanto, o estudo teve como base de análise três coleções aprovadas pelo PNLD 2017², válido para os anos de 2018 e 2019: Geografia Espaço e Vivência, Expedições Geográficas e Vontade de Saber, destinados a estudantes dos $6^{\circ}$ e $7^{\circ}$ anos.

O trabalho está estruturado na seguinte ordem: além da introdução, das considerações finais e das referências que embasaram o trabalho, na primeira parte apresenta-se a metodologia adotada para sua realização. Na segunda, contextualizam-se as temáticas pesquisadas e o livro didático como objeto de estudo. Na terceira, descrevem-se os resultados da análise realizada.

\section{PASSO A PASSO PARA O DESENVOLVIMENTO DA PESQUISA}

Para o estudo das obras, utilizou-se o método qualitativo de pesquisa, o qual, segundo Volpato (2013, p. 217), "trabalha com a qualidade dos itens". Para exploração, levantamento e análise do conteúdo, Bardin (1977) ofereceu as técnicas de tratamento de dados de pesquisa qualitativa; ou seja, a técnica metodológica de Análise do Conteúdo. Esta técnica pode ser aplicada em vários discursos e em todas as formas de comunicação. Soma-se à essa metodologia o levantamento bibliográfico sobre os temas e o estudo das obras escolhidas para análise, conforme a relação detalhada na figura 1 .

\footnotetext{
${ }^{2}$ Em conformidade com o período de realização da pesquisa, os livros analisados são do PNLD 2017, contudo os colégios, que cederam os livros para a pesquisa, receberam livros do PNLD 2019, para uso a partir do ano de 2020. Observou-se que neste PNLD o tempo de utilização dos livros didáticos teve o aumento de um ano. A preocupação manifestada pelos professores da escola, via conversa telefônica, devido a necessidade de distanciamento físico em razão da Pandemia da Covid-19, é com o aumento do tempo de vigência do uso do livro em sala de aula, considerando que parte do conteúdo, poderá sofrer defasagem, não permitindo aos estudantes acesso a informações atualizadas. Outrossim, o relato de professores das escolas públicas Colégio Estadual do Campo Iraci Salete Strozak de Rio Bonito do Iguaçu e do Colégio Estadual Padre Chagas de Guarapuava - Paraná, a coleção projeto Araribá Mais da Editora Moderna foi a adotada pelo Governo do Estado e enviada para todos os colégios no ano de 2020. Observa-se que a Coleção Araribá Mais da Editora Moderna, não foi analisada por esta pesquisa.
} 
A análise ou estudo dos livros didáticos apoiou-se nos seguintes itens: o texto escrito (as narrativas), o uso de imagens, gráficos, quadros, tabelas, mapas, e a organização do conteúdo.

Figura 1 - Títulos e autores das Coleções analisadas pela pesquisa

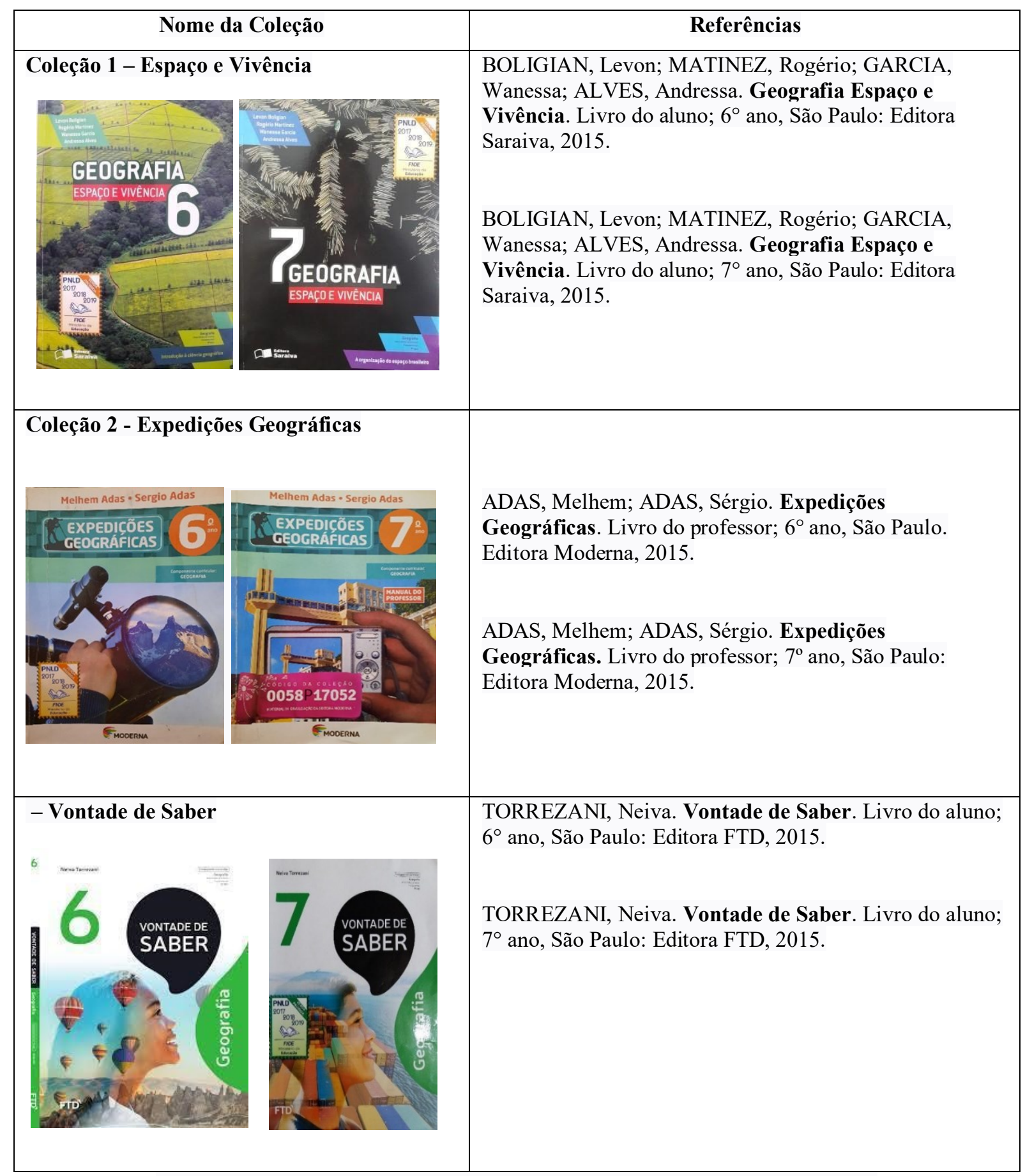

Fonte: Livros didáticos estudados pela pesquisa organizados pelas autoras (2020) 
Por fim, apresenta-se a Ficha Roteiro elaborada para a análise dos conteúdos (Figura 2).

Figura 2 - Ficha Roteiro para análise dos Livros didáticos

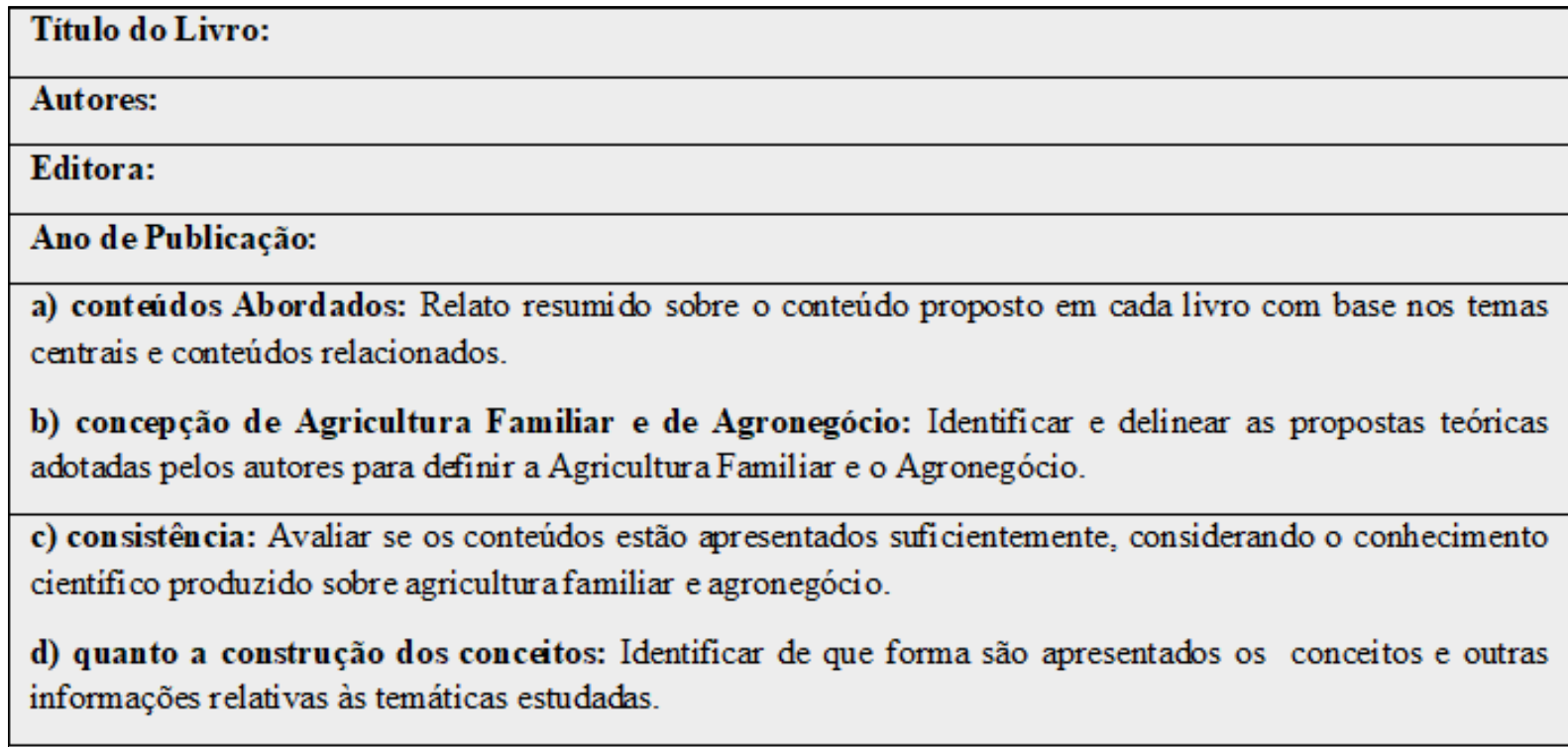

Org. A autora (2018).

Apresentados o propósito e o plano a partir dos quais o trabalho foi desenvolvido, dáse início ao referencial teórico que deu sustentação ao estudo. Os resultados, neste texto, não foram organizados de forma rígida, seguindo a ordem exata expressa na ficha roteiro.

\section{CONTEXTUALIZAÇÃO DA AGRICULTURA BRASILEIRA E DO LIVRO DIDÁTICO COMO OBJETO DE ESTUDO}

Para tratar do desenvolvimento da agricultura brasileira, não se pode esquecer da colonização do Brasil, que teve consideráveis impactos na configuração do campo brasileiro, cujas cicatrizes permanecem. Desde então, o Brasil já exercia o papel de produtor de commodities, priorizando a monocultura, modelo que se conserva resistente e superiorizado e, por vezes, estigmatiza e inferioriza a produção familiar (ALVES, 2010). Para observar tal discrepância, basta consultar a liberação de recursos ${ }^{3}$. No campo brasileiro, encontram-se sistemas de Agricultura em plena disputa política e econômica, tendo, de um lado, fortemente

\footnotetext{
${ }^{3}$ Plano Safra 2020/2021 - Para a agricultura familiar foram destinados R\$ 39,34 bilhões via financiamento pelo Pronaf, com juros de 3\% e 4,5\%. Desse valor, são R\$ 21,74 bilhões para custeio e comercialização, e R\$ R\$ 17,6 bilhões para investimentos. Para o Agronegócio foram destinados 251,2 Milhões (MAPA, 2021).
} 
protegidos pelo Estado, os grandes proprietários agrícolas, que compõem o chamado agronegócio; e de outro, os sujeitos que trabalham com a agricultura de base familiar, que agrega um conjunto de formas de organização social, econômica e de funcionamento. Conforme explica Barros (2018, p. 177-178),

De um lado, o agronegócio ou agribusiness, representado pela burguesia agrária e articulado ao capital financeiro internacional; do outro, a agricultura camponesa com base na produção familiar e de alimentos, sustentada pelos/as trabalhadores/as rurais assentados, sitiantes, posseiros, arrendatários, parceiros, meeiros e pequenos produtores rurais.

O sistema agrícola do agronegócio é diferente do sistema agrícola do camponês. No primeiro, a acumulação, a monocultura, o trabalho assalariado e a produção em grande escala são algumas das principais referências. No segundo, a reprodução, a biodiversidade, a predominância do trabalho familiar e a produção em pequena escala são algumas das características de destaque. Nesse sentido, notam-se as duas faces que a agricultura brasileira possui: uma da Agricultura Familiar e outra do Agronegócio (WELCH; FERNANDES, 2008).

A opção pelo conceito Agricultura familiar se deve a sua utilização nos livros didáticos. Todavia, adota-se uma definição aberta/ampla de agricultura familiar, como a praticada por um grupo social, ligado por laços de parentesco (família), que possui em comum uma propriedade ou pedaço de terra para desenvolver atividades agropecuárias. Essa definição abrange as estratégias individuais e coletivas da família usadas para a sua reprodução, incluindo atividades não-agrícolas e eventuais contratações de mão de obra (SCHNEIDER, 2003). Incorporamos, também, o pensamento de Bombardi (2003), pois concordamos que é difícil diferenciar agricultor familiar de camponês, tendo em vista apenas o seu grau de tecnificação e sua inserção no mercado. "Embora os camponeses estejam totalmente inseridos no mercado sabemos que o mercado sempre fez parte da vida camponesa e esta relação é o meio para manter e ampliar a sobrevivência e não o fim e objetivo da vida" (BOMBARDI, 2003, p. 113). Com base em DelGrossi (2019), formalmente a definição de agricultura familiar brasileira está prevista na Lei ${ }^{\circ} 11.326$, de 24 de julho de $2006^{4}$ (BRASIL, 2006). Temos no país, de um lado, as forças

\footnotetext{
${ }^{4}$ Em seu art. $3^{\circ}$ temos a seguinte definição: Considera-se agricultor familiar e empreendedor familiar rural aquele que pratica atividades no meio rural, atendendo, simultaneamente, aos seguintes requisitos: I - Não detenha, a qualquer título, área maior do que 4 (quatro) módulos fiscais; II - Utilize predominantemente mão de obra da própria família nas atividades econômicas do seu estabelecimento ou empreendimento; III - Tenha percentual mínimo da renda familiar originada de atividades econômicas do seu estabelecimento ou empreendimento, na forma definida pelo Poder Executivo; (Redação dada pela Lei n ${ }^{\circ} 12.512$, de 2011); IV - Dirija seu estabelecimento ou empreendimento com sua família. $\S 1^{\circ} \mathrm{O}$ disposto no inciso I do caput deste artigo não se aplica quando se tratar
} 
produtivas do Agronegócio; e de outro, da agricultura familiar, fato que tem marcado a agricultura nacional. Esta última é compreendida, genericamente, de forma a contemplar todos os agricultores que não integram a agricultura não familiar ou patronal.

No que tange à Geografia escolar, sabe-se que surgem questões sobre as temáticas relacionadas ao rural (agrário e agrícola), porque estão presentes na vivência dos estudantes rurais e urbanos, e ambos precisam ter conhecimento da realidade do campo e a sua complexidade. Nesse sentido, cabe à geografia levá-los a compreender o espaço produzido pela sociedade, suas desigualdades e contradições, as relações de produção que nela se desenvolvem, e a apropriação que essa sociedade faz da natureza (OLIVEIRA, 1994). A abordagem desses conteúdos precisa ser feita como parte do processo de conscientização e inalienação necessários à formação dos estudantes como sujeitos pensantes e atuantes na sociedade. Trata-se de um ensino que contribua para uma educação que tem a função de conscientização do sujeito (SNYDERS, 2005) e mudança social, e torne o livro didático um aliado no processo de ensinoaprendizagem e contribua para a formação de cidadãos críticos. (VESENTINI 1998). Sob tal foco, a forma de encaminhar a discussão de um texto deve possibilitar abertura para o questionamento e a indagação, e que por sua vez, direcione a compreensão dialética da produção do espaço agrário, produzindo um ensino crítico da geografia (BEM, 2011).

A análise do conteúdo textual realizada é fruto do trabalho de identificação do conteúdo correspondente aos temas e das temáticas que gravitavam em torno deles; da análise do conteúdo e imagens apresentados nesses materiais que, sem dúvida, visaram a melhorar e ilustrar o conteúdo trabalhado e, por fim, a avaliação de como, ao nosso ver, esses conteúdos podem contribuir para a formação do pensamento crítico.

\section{A AGRICULTURA FAMILIAR E O AGRONEGÓCIO NOS LIVROS DIDÁTICOS DE GEOGRAFIA: A ANÁLISE}

Vejamos: no livro do $6^{\circ}$ ano da Coleção 1 - Geografia, Espaço e Vivência, as temáticas estão concentradas no Capítulo 3, intitulado "Os Espaços da Produção" (BOLIGIAN et al., 2015 a , p. 26), subdividido em subcapítulos, cujos temas são: a agricultura, a produção

de condomínio rural ou outras formas coletivas de propriedade, desde que a fração ideal por proprietário não ultrapasse 4 (quatro) módulos fiscais (BRASIL, 2006). 
agrícola brasileira, a criação de animais, a bovinocultura brasileira, a extração de recursos naturais, transformação das matérias-primas e por último, um subcapítulo sobre a atividade industrial no Brasil.

No que diz respeito aos temas centrais e aqueles que os envolvem, a agricultura é definida como "Atividade econômica que envolve o cultivo de plantas com algum tipo de utilidade para o ser humano" (BOLIGIAN et al., 2015a, p. 26). Os autores classificam a agricultura em dois subsetores: agricultura moderna comercial, que é definida como "o cultivo de espécies vegetais destinadas à produção de matérias-primas para a indústria"; e a agricultura familiar é definida como "a produção destinada ao sustento dos próprios agricultores e de sua família. " (BOLIGIAN et al., 2015a, p. 26). Os autores ainda ressaltam que, "quando a agricultura familiar gera uma pequena produção excedente, costuma ser comercializada pelos agricultores em feiras ou no comércio local” (BOLIGIAN et al., 2015a, p. 26). Entende-se que os autores poderiam ter se apropriado da legislação e/ou conceituação oficial da agricultura familiar $^{5}$ e da agricultura moderna empresarial (agronegócio). Todavia, acreditamos que a intenção dos autores, de facilitar aos estudantes a compreensão dos temas, pode ter provocado a simplificação e empobrecimento conceitual. Ao abordar o agronegócio, é importante mostrar sua complexidade como modelo de desenvolvimento econômico controlado por corporações transnacionais, que trabalham com uma ou mais commodities e atuam em diversos outros setores da economia (WELCH; FERNANDES, 2008). De acordo com Welch e Fernandes (2008), o sistema agrícola camponês não é parte do agronegócio; porém, como o capital controla a tecnologia, o conhecimento, o mercado e as políticas agrícolas, os camponeses estão dependentes da sua hegemonia. É indiscutível que essas agriculturas não são estanques nem independentes, muito pelo contrário: no interior de cada uma delas, a consideração da complexidade de atores, interesses e conflitos é inevitável. No livro em pauta, os autores introduziram um texto abaixo de duas imagens (em uma espécie de legenda), uma descrevendo a agricultura moderna comercial (agronegócio); e outra, a agricultura familiar. Entendemos que

\footnotetext{
${ }^{5}$ A Lei $n^{\circ} 11.326$, de 24 de julho de 2006, pode ajudar na construção dos pré-requisitos para ser considerado agricultor familiar. Todavia, se é importante que o professor faça os complementos necessários, quer dizer, das outras funções como a reprodução da biodiversidade, a predominância do trabalho familiar e a garantia de renda, a produção de alimentos para o autoconsumo bem como para a venda, especialmente dos produtos que compõe a dieta alimentar brasileira.
} 
essa descrição poderia compor o texto principal do livro de forma a assegurar uma melhor compreensão do assunto.

Nos livros didáticos estudados, são recorrentes as informações complementares por meio de boxes informativos que trazem o detalhamento necessário ao texto principal. Contudo, a questão que fica é: será que esses textos são lidos com a mesma atenção que o texto que ocupa o centro da página?

Boligian et al. (2015a), no subcapítulo A produção agrícola brasileira, destaca as milhões de toneladas de produtos agrícolas, como soja, café, milho, arroz, feijão, mandioca, cana-de-açúcar, laranja, cacau, algodão, fumo, tomate e banana. Apontam, também, a expansão da agricultura moderna comercial (voltada para o agronegócio), principalmente nas grandes propriedades das regiões Sul, Sudeste e Centro-Oeste do Brasil. Segundo os autores, "essas propriedades buscam o aumento da produtividade agrícola, ou seja, o aumento da quantidade de produtos colhidos por área plantada" (BOLIGIAN et al., 2015, p. 27).

Contrastando com o pouco detalhamento dos temas e a centralidade ocupada pela representação numérica da produção e produtividade, são valorizadas as ilustrações e os mapas como forma de mostrar a distribuição das atividades e produtos agrícolas. Posteriormente, em texto complementar, trata-se da importância econômica e social da agricultura, enfatizando fatores como: produção de alimentos, oferta de trabalho, fornecimento de matérias-primas para fabricação de alimentos ou de outros produtos como fios para tecidos, óleos vegetais, entre outros, e geração de riqueza com a atividade de exportação de produtos agrícolas. Chama-se a atenção para a força que ganham os termos exportação, moderno e produtividade. É notória a preocupação dos autores em explicar termos que nem sempre são conhecidos pelos alunos, em atendimento ao que recomenda o PNLD. Esse vocabulário técnico, ao nosso ver, estimula os estudantes para o aprofundamento do conteúdo e para a compreensão integral do texto. Do mesmo modo, as sugestões de pesquisa em outras fontes pretendem desenvolver a capacidade de pensamento crítico para sínteses, comparações, interpretações e conclusões sobre o conteúdo tratado.

O livro de $7^{\circ}$ ano aborda a atividade agropecuária no Brasil, a qual Boligian et al. (2015b) denominam como a prática conjunta das atividades da agricultura e da pecuária que ocupa papel de destaque na economia nacional. Os autores atribuem a expansão da agropecuária 
ao aumento do nível tecnológico nas propriedades rurais, qualificado como o uso de máquinas e implementos, defensivos agrícolas, adubos e fertilizantes, práticas avançadas de cultivo e criação; uso de sementes selecionadas e animais com melhoramento genético. Afirmam que, “ainda que o nível tecnológico tenha se expandido por várias áreas rurais, o setor agrário moderno convive com setores tecnicamente mais atrasados" (BOLIGIAN et al., 2015b, p. 64), indicando como "atrasados" os agricultores que trabalham com técnicas de produção tradicionais, os camponeses, pequenos agricultores, etc. Em um dos trechos, alegam que: "Nessas propriedades, as lavouras são cultivadas com a utilização, por exemplo, de arados de tração animal, enxadas e foices. Já os animais são criados soltos sem receber maiores cuidados" (BOLIGIAN et al., 2015b, p. 65). Os autores assinalam que a utilização de técnicas arcaicas diminui a produtividade das atividades agropecuárias de maneira significativa, já que as lavouras ficam mais vulneráveis às pragas e doenças, também às oscilações do tempo, o que prejudica as colheitas. Os animais, por sua vez, demoram mais para crescer e engordar. Muitas vezes, não atingem o peso ideal, além de contraírem doenças mais facilmente. De forma bastante sutil há, nos textos, um forte apelo e defesa ao uso de produtos químicos, e a negação do uso de maquinários tradicionais ou rústicos, além da menção à criação de animais à solta, que não recebe os devidos cuidados. Tais afirmações não citam as fontes dessas informações, parecendo juízo de valor. Esse discurso defende o enquadramento de todos os agricultores na lógica produtivista.

Com relação à parte gráfica e ilustrativa do livro, merecem destaque pelo colorido que trazem, mas delegam o trabalho de leitura e interpretação ao professor.

A Agricultura Familiar é dividida entre médios e pequenos agricultores. Esta menção é equivocada, se considerada a definição oficial de Agricultura Familiar, a qual compreende agricultores que possuem área de até 4 módulos fiscais, ou seja, o agricultor familiar é um pequeno proprietário ${ }^{6}$. Os autores afirmam que ambos desenvolvem a chamada agricultura familiar, e recebem do governo recursos insuficientes para atender às suas necessidades. "Isso dificulta a modernização de suas propriedades, que, em geral, estão voltadas para a produção

\footnotetext{
${ }^{6}$ Em relação ao tamanho da área, os imóveis rurais são classificados em: Pequena Propriedade - o imóvel de área compreendida até 4 (quatro) módulos fiscais; Média Propriedade - o imóvel rural de área superior a 4 (quatro) e até 15 (quinze) módulos fiscais; Grande Propriedade - o imóvel rural de área superior a 15 (quinze) módulos fiscais. A classificação é definida pela Lei 8.629, de 25 de fevereiro de 1993 e leva em conta o módulo fiscal (e não apenas a metragem), que varia de acordo com cada município (INCRA, 2020).
} 
de culturas alimentares, como o feijão, a mandioca e o arroz" (BOLIGIAN et al., 2015b, p. 66). Complementarmente, trazem um texto intitulado Pequenos proprietários, grandes brasileiros (EMBRAPA, 2015), e um gráfico com os estabelecimentos rurais da agricultura familiar para leitura e análise. Nesse texto, os autores destacam que a maior parte dos agricultores brasileiros vive em pequenas e médias propriedades, nas quais o trabalho é feito pela própria família. Por disporem de poucos recursos, em geral, suas lavouras apresentam baixa produtividade. Observa-se que há, nos textos, uma narrativa generalizante de que toda pequena ou média propriedade tem baixa produtividade, justamente porque tem dificuldades de modernizar a sua estrutura de produção agrícola. Todavia, destacam que, "ainda assim, os pequenos proprietários são responsáveis pela produção de aproximadamente três quartos dos alimentos consumidos no país” (BOLIGIAN et al., 2015b, p. 67). Fernandes (2006a) reforça que esse segmento de agricultores é responsável por mais da metade da produção do campo, e não aparece como grande produtor. Concorda-se que se trata de uma estratégia do agronegócio para ser beneficiado/privilegiado com a maior parcela do crédito agrícola (FERNANDES, 2006a).

Nessa coleção, a ideia nuclear é o entendimento e defesa da supremacia do moderno frente ao tradicional. Nesse sentido, chamamos José de Souza Martins (2014, p.23), que ajuda a refletir sobre o que a modernidade pode significar, e questiona: "o quanto de passado existe, enquanto propriamente passado, nas práticas agrícolas e na organização social dos grupos humanos que à agricultura se dedicam? " Martins afirma que o fato de um grupo social, uma comunidade ou um bairro rural permanecerem organizados com base em valores comunitários e tradicionais não os torna avessos à tecnologia moderna, nem os torna personagens do passado, desfavoráveis aos fascínios do futuro. Isso os torna críticos em relação às imensas irracionalidades que podem atravessar o uso dessa tecnologia. "Se conseguissem interessar-se pelo aparentemente irrelevante, entenderiam o quanto o irrelevante é decisivo na vida de cada dia das populações do campo e da cidade” (MARTINS, 2014, p. 23). Martins (2014, p. 24) acrescenta que "a tradição é a grande referência social de pensamento crítico das populações rústicas em relação aos riscos corrosivos da modernização antagônica aos costumes, e até socialmente destrutiva".

O Capítulo 6, intitulado As atividades do Campo Brasileiro, trata sobre a Biotecnologia, afirmando que "os conhecimentos e as técnicas criados pela Embrapa contribuíram, por exemplo para que extensas áreas de Cerrado se tornassem agricultáveis, o que elevou em cerca 
de 50\% a produção de grãos em nosso país” (BOLIGIAN et al., 2015b, p. 71). Contudo, ignorase a importância do Bioma Cerrado e externalidades ambientais, como a erosão e perda de solos férteis, comprometimento dos recursos hídricos, desmatamento, destruição de habitats naturais, a intensa utilização de insumos químicos, mecanização intensiva, entre outras, fato que poderia mostrar como a sojicultura tem atuado como um dos grandes agentes no processo de perda de biodiversidade do Cerrado (QUEIROZ, 2009). Todavia, existem alguns problemas no conteúdo do livro, dentre os quais podemos destacar, no tratamento dos impactos ambientais causados pela agricultura moderna faz-se uma abordagem superficial, não demonstrando ao leitor os conflitos socioambientais que continuam a se processar no território brasileiro;

Além das observações que destacamos com a análise, constatamos que, nela, ocupa centralidade a descrição, a quantificação e a distribuição da agricultura do Brasil, com ausência de espacialização dos tipos de agriculturas e produtos agrícolas no Brasil, bem como a ausência, no texto escrito, dos sujeitos sociais, que são os motores da agricultura brasileira.

Coleção 2 - Expedições Geográficas - No livro do $6^{\circ}$ ano, os autores abordam a agricultura a partir da sua relação com os fatores naturais (clima, solo, relevo, entre outros), indicando o tipo de clima em que se desenvolvem, por exemplo, o amendoim e o algodão, que crescem em clima seco e quente. Para tratar dessa relação, os autores inserem um mapa do mundo com algumas plantas cultivadas. Ao abordarem os solos, explicam as condições favoráveis e desfavoráveis para a agricultura e, quanto à produtividade agrícola e ao processo de adubação, apontam o relevo, que pode ser elemento restritivo ou facilitador para a prática agrícola. Na sequência, seguem tratando da organização da produção da agricultura brasileira, que se estende por quase todo o território mediante espacialização no mapa dos principais produtos agrícolas. Isso é relevante, pois pode levar os estudantes ao entendimento de quão distintas são as práticas agrícolas nos diferentes pontos do território brasileiro, cada qual com características físicoambientais marcantes. Citam-se 4 tipos básicos de organização do espaço para a produção agrícola brasileira: "o latifúndio; a unidade familiar produtora de bens agrícolas para o mercado; a chamada agricultura familiar, a unidade familiar de subsistência e a empresa agrícola, em que estão inseridos o agronegócio e a agroindústria (ADAS; ADAS, 2015a, p. 224). 
O latifúndio é definido pelos autores como a grande propriedade rural, a qual não tem toda a sua terra cultivada, marcado pelo subaproveitamento, explorado, geralmente, através de técnicas tradicionais, e apresenta baixa produtividade. Vimos em Fernandes (2006a) que o agronegócio é um novo tipo de latifúndio ainda mais amplo, agora não só concentra e domina a terra, mas a tecnologia de produção e as políticas de desenvolvimento também.

A definição de agricultura familiar, nesse livro, traz uma descrição que se aproxima do entendimento oficial, conforme os dados do Censo Agropecuário de 2006, sobre a agricultura familiar no Brasil.

\begin{abstract}
Nesse tipo de organização da produção agrícola, o uso da terra é feito por pequenos proprietários e arrendatários, com trabalho fundamentalmente familiar, havendo, às vezes, a contratação de mão de obra assalariada. A agricultura familiar, que visa abastecer principalmente o mercado interno, é responsável por mais da metade da produção de alimentos no Brasil - arroz, feijão, frutas, hortaliças, cebola, batata, entre outros (ADAS; ADAS, 2015a, p. 224).
\end{abstract}

Sobre as condições de produção da agricultura familiar, os autores mencionam que a unidade familiar de subsistência:

\begin{abstract}
É realizada em pequenas propriedades, muitas delas classificadas como minifúndios, com a utilização de técnicas tradicionais e mão de obra familiar. Nesse caso, a produção tem por objetivo atender às necessidades alimentares da família que a pratica. [...]. Parte dos produtos cultivados e da criação de animais é vendida para adquirir sal, óleo, outros alimentos e produtos de que a unidade familiar necessita. Em geral, o pai ou os filhos mais velhos se empregam em outras propriedades como trabalhadores permanentes ou temporários (boias-frias) para complementar a renda familiar (ADAS; ADAS, 2015a, p. 225).
\end{abstract}

Com relação aos minifúndios citados, é importante dialogar com os estudantes sobre o que são e quais são as dificuldades que os proprietários ou posseiros que trabalham em minifúndios enfrentam para o desenvolvimento da agricultura, considerando que o tamanho ${ }^{7}$ destas terras é inferior ao módulo fiscal dos municípios. As empresas agrícolas, por sua vez, "são caracterizadas como, unidades de produção avançadas do ponto de vista tecnológico e podem ocupar grande, média e pequena extensão de terra [...] utilizam técnicas controladas de

\footnotetext{
7 "Em relação ao tamanho da área, os imóveis rurais são classificados em: Minifúndio: imóvel rural com área inferior a 1 módulo fiscal; Pequena Propriedade: imóvel com área entre 1 e 4 módulos fiscais; Média Propriedade: imóvel rural de área superior a 4 e até 15 módulos fiscais; Grande Propriedade: imóvel rural de área superior a 15 módulos fiscais. A classificação é definida pela Lei 8.629, de 25 de fevereiro de 1993 e leva em conta o módulo fiscal, que varia de acordo com cada município" (INCRA, 2020, grifos do autor).
} 
irrigação e contam com a assistência técnica de engenheiros agrônomos" (ADAS; ADAS, 2015a, p. 225). Devido ao uso de tecnologias, apresentam ganho em produção e produtividade, e empregam trabalhadores permanentes e temporários. Nessa coleção também são abordados os impactos ambientais causados pela agricultura moderna, como a compactação e erosão do solo, a contaminação da água de rios e lençóis subterrâneos, e até mesmo danos à saúde humana (ADAS; ADAS, 2015a). Os autores salientam que o uso de máquinas agrícolas facilita a prática da agricultura, mas ao mesmo tempo, esses maquinários ajudam na compactação do solo, fator que dificulta a infiltração de água da chuva, contribuindo para aumentar o escoamento superficial. Apontam o uso de agrotóxicos como causador de danos à saúde humana, dos animais e ao meio ambiente, e por isso as pessoas vêm buscando consumir produtos orgânicos, cultivados com adubo natural e controle biológico. Neste sentido, acredita-se que a agroecologia nas escolas, a produção orgânica e tudo o que contribui para a sustentabilidade compõem um conjunto de temas estratégicos para a crítica à política da agricultura convencional e distribuição agrária no Brasil, além de proporcionar conhecimento sobre agriculturas de base ecológica.

No livro didático do $7^{\circ}$ ano, a Unidade III - O Campo e as Cidades no Brasil, trata das atividades do campo brasileiro: a agropecuária no Brasil, gêneros agrícolas para indústria e para exportação; Cooperativas e agroindústrias. No Capítulo Os problemas no campo brasileiro são abordados os seguintes conteúdos: O subaproveitamento do espaço rural, a concentração de terras, a reforma agrária, a utilização do solo. Os conteúdos referentes ao agronegócio e à agricultura familiar são chamados de Culturas Especializadas e Grandes Culturas Comerciais. Em um mapa do Brasil são demonstradas as seguintes culturas especializadas e as principais regiões produtoras: caju, palmito, amendoim, batata, pêra, trigo, fumo, aveia, malva, pimentado-reino, juta, guaraná, sisal, dendê, cacau e coco. Já as grandes culturas comerciais, o café, a cana-de-açúcar, o arroz, o feijão, a laranja, a soja, o algodão, o milho, entre outras, “ocorrem em vastas áreas nas diversas regiões do Brasil, demonstrando o enorme potencial agrícola do país" (ADAS; ADAS, 2015a, p.100), isso porque estas se modernizaram nos últimos quarenta anos. Sua elevada produtividade decorre do uso de tecnologia e técnicas agrícolas avançadas, como a seleção de sementes, mudas, correção do solo, mecanização e assistência agronômica. Dá-se destaque à primeira posição do Brasil como produtor mundial de café, cana-de-açúcar e cítricos; e segundo maior produtor de soja, perdendo apenas para os Estados Unidos (os dados 
são de 2014/2015). No subtítulo soja e cana-de-açúcar: custos ambientais e sociais, os autores ponderam sobre o avanço da cultura da soja, juntamente com a pecuária bovina e a exploração madeireira em direção à Amazônia, que tem sido responsável por grandes desmatamentos na floresta. Outro tema tratado é a Desigualdade no Campo, e enfoca a raiz histórica da grande propriedade rural. Mesmo que de maneira breve, trata-se da desigualdade no campo e da raiz histórica da implantação dos latifúndios produtivos e improdutivos. É discutida a dificuldade histórica de acesso à terra por parte de milhões de trabalhadores brasileiros, e a partir disso, mostra-se como e onde surgiram os movimentos sociais, argumentando que, para as famílias que moram nos assentamentos terem condições de trabalhar na terra, há necessidade de crédito, assistência agronômica, estrada para o escoamento da produção, rede de energia elétrica, dentre outros incentivos. Entretanto, "na maioria desses assentamentos, várias dessas condições não foram implantadas, muitas famílias não obtiveram sucesso no trato da terra" (ADAS; ADAS, 2015a, p. 103). Os autores ainda enfatizam as ações humanas inadequadas e contraproducentes, isto quer dizer, aquelas que devastam os bens naturais vitais no planeta.

Como nos demais livros, os autores têm se preocupado com a inserção de figuras que mostrem paisagens e cenários que ajudem na elucidação do conteúdo trabalhado pelo professor. Desse modo, acreditamos que se busca potencializar a capacidade que os alunos têm de procurar alternativas para emoldurar o mundo, tornando-o livre de exploração e dominação, conforme sugere a concepção marxista de pensamento crítico.

Coleção 3 - Vontade de Saber - No livro do $6^{\circ}$ ano, a agricultura é abordada a partir da Agropecuária $^{8}$, e Torrezani (2015a) traz dados de produtividade, destacando os produtos mais cultivados no mundo e a sua quantidade, que é dada em toneladas, fazendo um comparativo entre a produção de milho dos EUA e Brasil. Na sequência, trabalha com a divisão da agricultura em Agricultura Moderna e Agricultura Tradicional. A primeira é definida pela autora como a

Responsável pela produção tanto de alimentos quanto de matérias-primas empregadas na fabricação de bens e de fontes energéticas para o abastecimento de outros setores da economia, como a indústria e o comércio. Por isso, também pode ser chamada de agricultura comercial. Nessa atividade agrícola, são empregados maquinários e implementos agrícolas altamente sofisticados, sementes selecionadas,

\footnotetext{
8 Tendo Diniz (1984, apud Suzuki, 2007) como base, entende-se agricultura como o conjunto de atividades, relativas aos cultivos e aos sistemas criatórios, presentes no campo. São várias concepções que partilham da ideia de que agricultura é muito mais do que a prática dos cultivos, envolvendo, também, a criação dos animais.
} 
insumos agrícolas, como fertilizantes, além de herbicidas e fungicidas para o controle de pragas e doenças nas plantações. Em geral, as propriedades agrícolas que desenvolvem a agricultura moderna, se caracterizam por apresentarem elevada produtividade (TORREZANI, 2015a, p. 193).

A definição de agricultura moderna traz, no centro, a alta produtividade e os elevados lucros que gera. Para Fernandes (2006a), pode servir de estratégia para ocultar o caráter concentrador, predador, expropriatório e excludente, para revelar somente o caráter produtivo. Não fica claro o posicionamento da autora, na medida em que apenas descreve a agricultura, seus processos de produção, tipos e quantidade. Não há menção aos problemas de ordem econômica e social provocados pela implantação do padrão moderno de agricultura.

A Agricultura Tradicional foi conceituada pela autora como a que faz o uso restrito de máquinas sofisticadas e insumos agrícolas, que utiliza técnicas tradicionais de cultivo, como arados de tração animal, o trabalho é realizado por mão de obra familiar, e as áreas destinadas à prática desse tipo de agricultura, em geral, são pequenas e apresentam baixa produtividade. "Isso se deve principalmente à ausência de investimentos em recursos tecnológicos capazes de ampliar a produção" (TORREZANI, 2015a, p.193).

Para tentar compreender essa negação da agricultura tradicional frente à moderna e, de certa forma, buscar um entendimento do que ela pode representar/significar para aqueles que a desenvolvem, apoiamo-nos em Martins (2014), quando afirma que a tradição e o tradicionalismo se expressam de diferentes modos. Na consciência do homem comum, são referências para ele compreender criticamente as transformações sociais pelas quais passa, e quando se depara com a corrosão de seu modo de vida. Contudo, a tradição é também um meio de orientação autodefensiva e transformadora de suas ações. Desse modo, o mundo rural pode ser cada vez mais moderno, sendo, ao mesmo tempo, cada vez mais tradicional. Para o autor, essa é a dialética do processo social.

Martins (2014) destaca, também, que os agentes econômicos da agricultura familiar diferem do grande empresário rural, não pelo tamanho, mas pelos valores sociais e pela lógica social, econômica e política que os norteia. Eles podem ver e valorizar a terra que está cotidianamente perto deles, diferentemente do grande empresário, que se relaciona com a terra pela mediação da renda fundiária, de uma abstração. O pequeno proprietário vê a terra como mediação e condição de um modo de vida, com valor de uso. 
Com o subtítulo A importância da agricultura familiar no Brasil para a produção de alimentos, Torrezani (2015 a p.195) apresenta números da produção no Brasil, e afirma que a maior parte da produção de alimentos é fruto do trabalho dos agricultores familiares. Também segue afirmando que, no Brasil, $86 \%$ das propriedades rurais possuem área menor que 100 hectares. Nelas, geralmente a terra é cultivada por membros da própria família, sem o emprego de mão de obra externa. Muitos agricultores familiares, além de cultivarem lavouras como arroz e feijão, criam animais, como aves e gado para a produção leiteira (TORREZANI, 2015a, p.195). Desse modo, fica fácil de observar a expressiva produtividade da agricultura familiar quando se trata de alimentos que compõem a cultura alimentar dos brasileiros. Esses dados evidenciam a importância da agricultura familiar/tradicional como segmento bastante complexo, e que não se pode reduzi-lo ao índice de produtividade. Nesse sentido, Fernandes (2006a) lembra que a agricultura camponesa não é adepta do produtivismo, quer dizer, não produz uma única cultura e exclusivamente para o mercado, e não faz uso intensivo de insumos externos. Sua alavanca na produção de alimentos está na diversidade, no uso múltiplo dos recursos naturais. Fernandes (2006a, on line) salienta que "onde há concentração de pequenos agricultores, a desigualdade é menor e o índice de desenvolvimento maior”.

No livro do $7^{\circ}$ ano, a autora dá ênfase à agropecuária moderna, a qual vem aumentando a produtividade desde o ano de 1970. Com relação à expansão da agricultura brasileira através do avanço da mecanização do campo, apresenta dois gráficos: um do aumento de tratores e outra de expansão da soja, sugerindo que o aumento do maquinário no campo está diretamente relacionado com o aumento da expansão agrícola. O uso de agrotóxico, chamado pela autora de defensivo agrícola, também é citado, mas não alerta que a utilização em excesso é prejudicial à saúde. Sobre a agricultura familiar/camponesa, não há espaço reservado para tal assunto, como no livro do $6^{\circ}$ ano. Geralmente, nessas propriedades, a produção é destinada ao sustento da família do agricultor, assim como parte dela é comercializada. Boa parte da produção das pequenas propriedades rurais abastece o comércio interno do país (TORREZANI, 2015b, p.74).

No Capítulo que trata O urbano, o rural e a economia brasileira, Torrezani (2015b, p. 74) qualifica as grandes propriedades rurais, ao afirmar que, "No espaço rural brasileiro existem também grandes propriedades agropecuárias equipadas com maquinários sofisticados e técnicas modernas de produção. Muitas dessas propriedades estão voltadas para a produção de gêneros destinados ao comércio externo". Ao tratar da Estrutura Fundiária, definida como “[...] a forma 
como as propriedades rurais estão organizadas ou distribuídas no território do país, de acordo com o seu tamanho" (TORREZANI, 2015b, p. 80), a autora mostra os problemas e conflitos que envolvem a terra no Brasil, e assinala que a estrutura fundiária é concentrada, no país. Acertadamente, a autora se utiliza do termo proprietários rurais e não agricultores, considerando que uma parte deles não exerce a função de produtor rural ou agricultor, apenas possui a propriedade da terra para obter renda dela, para fins de reserva de valor; ou seja, detémse a terra sem valor de uso, mas com valor de troca. Contudo, a questão fundiária não é tratada como um problema histórico, mas apresentada como uma falta de distribuição das terras. Torrezani (2015b) apresenta o contraste no campo entre lavouras modernas de boa produtividade, e aponta a existência de um setor agropecuário tecnicamente mais atrasado e pouco produtivo, sem contextualizar nenhuma das duas produções. Em nenhum momento são citadas formas alternativas de produção, e nem mesmo tratadas como distintas e com importantes peculiaridades.

No subtítulo Contrastes no Campo Brasileiro, a autora afirma que embora "a modernização do campo tenha ocorrido em várias propriedades agropecuárias, o espaço rural é marcado por grandes contrastes tecnológicos. [...] As propriedades rurais modernas convivem com muitos estabelecimentos onde as lavouras são cultivadas com técnicas tradicionais" (TORREZANI, 2015b, p. 79). A autora salienta que, “[...] no Brasil existe um setor agropecuário moderno que, geralmente, alcança boas produtividades e que coexiste com um setor agropecuário tecnicamente mais atrasado e, normalmente, pouco produtivo" (TORREZANI, 2015b, p. 79). São mencionados os inúmeros conflitos pela posse da terra, originários dessa contrastante estrutura fundiária e da ausência de uma reforma agrária. Entretanto, ao citar os sujeitos que participam da luta pela terra, afirma que são "pequenos proprietários que, por algum motivo, como dívidas contraídas com bancos, perderam suas terras, reivindicam atualmente o direito de resgatá-las” (TORREZANI, 2015b, p. 83). Não há, no livro, um questionamento mais firme sobre o aprisionamento das terras nas mãos da elite agrária brasileira, e sobre o processo de expropriação dos camponeses via pressão do agronegócio sobre as terras da agricultura familiar. Entretanto, a autora atribui o baixo aproveitamento da capacidade produtiva que o território possui, em razão da falta de incentivos por parte do governo ao setor agropecuário, à intensa concentração fundiária e à especulação imobiliária. Torrezani (2015b) também trata da regionalização da produção agropecuária e 
explora o tema em cada uma das regiões, com informações por meio de textos, gráficos e mapas. Nesse percurso, a autora trata da agropecuária e da agricultura de forma bastante detalhada, ficando muito claro o processo de hierarquização das regiões.

Com relação ao uso de imagens e linguagens diferentes para se comunicar com o aluno, Torrezani (2015b) trabalha o texto com imagens, sempre acompanhado de um glossário que consideramos basilar para melhor compreensão. Para exemplificar a Reforma Agrária, a autora traz uma imagem de uma paisagem rural cubana, argumentando que a Reforma Agrária em Cuba resultou em uma reestruturação política, social e econômica do país, até chegar ao modelo atual de distribuição mais igualitária das terras e melhor aproveitamento da produção, e lembra que quem controla a produção agropecuária cubana é o Estado. É claro que Brasil e Cuba apresentam realidades tão díspares que dificultam a análise comparativa.

Do mesmo modo, a autora, para tratar de reforma agrária, em um Box (TORREZANI, 2015b, p. 81), sugere ao aluno a leitura do Livro de Fernando Portela e Bernardo Mançano Fernandes (2004), que narra a história de Zé Saturno e Maria na luta pela reforma agrária em uma pequena cidade dominada pela monocultura da cana-de-açúcar. O texto complementar é bastante esclarecedor, no que diz respeito aos objetivos da Reforma Agrária no Brasil. Observamos que a autora tem procurado estimular, nos alunos, a pesquisa com vistas ao aprofundamento do conteúdo.

Por isso, compreende-se que usar o pensamento crítico significa levar o aluno a utilizar a razão para tentar comprovar os fundamentos dos seus pontos de vista e suas conclusões. Isto implica a tentativa de avaliar, o mais objetivamente possível, a qualidade de uma declaração ou afirmação em um texto. Como estamos tratando de um material a ser trabalhado no Ensino Fundamental, quem assume essa tarefa é o professor que, de forma lenta e gradual, vai despertando os alunos para a investigação sobre as bases que estruturam as ideias ou afirmações do livro didático. 


\section{CONSIDERAÇÕES FINAIS}

A apreciação dos livros didáticos selecionados para analisar os avanços e, quem sabe, a insuficiência no tratamento do conteúdo sobre a agricultura familiar e o agronegócio se fez imperativa, no sentido de que os conteúdos em questão são fundamentais no processo ensinoaprendizagem da Geografia Escolar.

As constatações nos permitem afirmar que existe necessidade de maior aprofundamento teórico nos conteúdos de geografia agrária, e que a crítica é basilar para o crescimento da ciência e dos conhecimentos geográficos construídos nas universidades, que devem estar presentes na Geografia Escolar.

Ao analisar as três coleções de livros didáticos de Geografia, observamos que o conteúdo de geografia agrária apresenta limites e possibilidades para a construção e exercício do pensamento crítico na escola. As Coleções 1 e 3, em particular, espelham a geografia positivista, onde a quantidade, a descrição matemática é priorizada, em detrimento do movimento da sociedade e das diversas e contínuas lutas pela apropriação do território. Aliás, poucas vezes os sujeitos que fazem esse acontecer são mencionados. Contudo, a coleção 2 avança mais nesse sentido, dá mais espaço para a geografia dos homens que o produzem que a dos produtos agropecuários. Apresenta e discute os temas que envolvem a agricultura brasileira, como a estrutura fundiária, os movimentos sociais e reforma agrária de forma mais abrangente. A forma de encaminhar a discussão, em várias partes do texto, possibilita aos alunos espaços para a indagação e reflexão, e direciona a compreensão dialética da produção do espaço agrário, construindo o pensamento crítico em sala de aula.

Conforme observamos, as coleções estudadas apresentam um problema de integração/articulação do conteúdo, no que tange à compreensão da totalidade espacial, devido à desconexão de temas como agricultura, contaminação das águas, desmatamento, erosão do solo e desmatamento, expansão da fronteira agrícola e conflitos pela terra, e a abordagem da agricultura por regiões, entre outros. Do mesmo modo, não existe uma discussão crítica a respeito do agronegócio e seus poderes, como a monopolização dos insumos pelas multinacionais, o comportamento dos preços dos produtos agropecuários, a territorialização do capital no campo, e a pressão para a expropriação dos agricultores familiares. 
Notamos falta de uma distinção clara e aprofundada entre os modelos de agricultura no campo, visíveis na paisagem geográfica, o agronegócio e a agricultura camponesa, bem como quais são as aproximações que esses dois segmentos estabelecem. Nesses materiais didáticos, a agricultura moderna e empresarial é caracterizada pela alta produtividade, modernidade e exportação. Já a agricultura familiar, por uma forte tessitura de uma agricultura de baixa produtividade, baixos incentivos governamentais, agricultura de subsistência e produção de parte dos alimentos.

As informações e afirmações poderiam ser mais elaboradas nos livros didáticos, em se considerando os temas-chave; em outras palavras, o agronegócio como um sistema de produção de comodities, que tem como fim o mercado externo, compõe o capital que controla a tecnologia, o conhecimento, o mercado, as políticas agrícolas, e que mantém a hegemonia, inclusive da qual depende o agricultor familiar. Por isso, paulatinamente, o termo familiar tem sido associado ao passado, atraso e pouca significância.

Nas três coleções analisadas, o sistema familiar de produção não comparece como parte de um contexto socioeconômico próprio e que deveria ganhar força e visibilidade. Quando se questiona o futuro das pessoas que subsistem do campo, se discute a problemática do êxodo rural e, consequentemente, a tensão social decorrente da desigualdade social no campo e nas cidades. É necessário levar o aluno ao entendimento de que a agricultura familiar é complexa, e que as unidades de produção rural divergem em termos de tamanho, capital e tecnologia, tornando as prioridades individuais diferentes.

Apenas na Coleção 2 as agriculturas alternativas e a agroecologia são apresentadas, fazendo um contraponto à agricultura moderna e mostrando que existem outras formas de produzir no campo, que fogem do padrão convencional de agricultura.

As temáticas centrais são abordadas em uma perspectiva econômica e quantitativa, pois são recorrentes os elementos e imagens que demonstram as preocupações dos autores com a produção e a produtividade, termos que ganham bastante destaque. Acreditamos que faltou uma aproximação do conteúdo a uma escala mais próxima dos professores e alunos, uma vez que muitas abordagens terminam na escala global, enquanto os elementos e dinâmicas regionais e locais foram pouco ressaltados. 
Podemos afirmar, com base na análise realizada, que no Ensino Fundamental está presente o conteúdo referente à agricultura brasileira, mas a discussão conceitual ainda se faz incipiente. Poderíamos avançar, na medida em que muitos conteúdos já revelam a transformação ocorrida e as derivações decorrentes. Se trabalhamos com a ideia de vários rurais, teríamos que trabalhar com as agriculturas brasileiras, dado que a dimensão cultural e as diferenças entre as regiões assumem significado diversos.

No contexto descrito, acreditamos que os conteúdos de geografia agrária nos livros didáticos do Ensino Fundamental precisam ser sempre revisados, passar pela crítica do que é produzido na universidade e, acima de tudo, pelo que a realidade evidencia no espaço geográfico brasileiro.

\section{REFERÊNCIAS}

ADAS, M. ADAS, S. Expedições Geográficas 6º. São Paulo: Editora Moderna, 2015A.

. Expedições Geográficas 7². São Paulo: Editora Moderna, 2015B.

ALVES, F. D. Trajetória teórico-metodológica da geografia agrária brasileira: a produção em periódicos científicos de 1939-2009. Tese (doutorado) - Universidade Estadual Paulista, Instituto de Geociências e Ciências Exatas, 2010. Disponível em: http://hdl.handle.net/11449/104306. Acesso em: 07 jul. 2019.

BARDIN, L. Análise de Conteúdo. Edições 70: Lisboa - Portugal, 1977.

BARROS, I. F. O agronegócio e a atuação da burguesia agrária: considerações da luta de classes no campo. São Paulo, 2018. Disponível em: http://www.scielo.br/scielo.php?script $=$ sci arttext\&pid $=S 0101-66282018000100175$. Acesso em: 22 ago. 2019.

BEM, A. A Geografia Agrária nos livros didáticos: primeiras aproximações para uma crítica do conteúdo que se ensina na escola. Revista Ensino Geografia, Uberlândia, v. 2, n. 3, p. 137 150, jul. /dez. 2011.

BOLIGIAN, L; MATINEZ, R; GARCIA, W; ALVES, A. Geografia Espaço e Vivência. Livro do aluno, $6^{\circ}$ ano, São Paulo: Editora Saraiva, 2015a.

$2015 b$.

Geografia Espaço e Vivência. Livro do aluno; $7^{\circ}$ ano, São Paulo: Editora Saraiva, 
BALAGUER MORA, P. A.. (2018). Geografía crítica y pensamiento crítico. Actualidades Pedagógicas, (72), 73-95. doi:https://doi.org/10.19052/ap.5232

BOMBARDI L M . O Papel da Geografia Agrária no debate teórico sobre os conceitos de campesinato e agricultura familiar. GEOUSP Espaço E Tempo (Online), (14), 107-117. 2003. Disponível em: https://doi.org/10.11606/issn.2179-0892.geousp.2003.123836. Acesso em: 10 jul. 2019.

BRASIL. Lei $\mathbf{N}^{\circ} \mathbf{1 1 . 3 2 6}$, de 24 de julho de 2006. Disponível em: http://www.planalto.gov.br/ccivil_03/_ato2004-2006/2006/lei/111326.htm. Acesso em: 15 mar. 2018.

Campos, A. Pensamiento crítico ( $1^{\text {a }}$ Ed.). Bogotá: Editorial Magisterio. 2007)

DELGROSSI. M. E. Algoritmo para delimitação da agricultura familiar no Censo agropecuário 2017, visando a inclusão de variável no Banco de dados do censo, disponível para ampla consulta. Brasília, 2019. Disponível em: https://sidra.ibge.gov.br/Content/Documentos/CA/Metodologia\%20Agricultura\%20famil iar\%20(IBGE)\%20DelGrossi\%20final\%205jun2019.pdf. Acesso em: 10 jun. 2020.

FERNANDES, B. M. Um nome para "modernizar" o sistema de latifúndio. 2006a.Disponível em: http://www.unesp.br/aci/jornal/211/supled.php. Acesso em: 10 jul. 2019.

; MOLINA, M. C. O campo da educação do campo. In: MOLINA, M. C. e JESUS, S. M. S. A. de (Org.). Por uma educação do campo: contribuições para a construção de um projeto de educação do campo. Brasília: Articulação Nacional "Por Uma Educação do Campo", 2004b. p. 53-91. (Por Uma Educação do Campo, 5).

Questões da Via Campesina. Anais do $6^{\circ}$ Congresso Brasileiro de Geógrafos. Goiânia, 2004c. Acesso: http://www.lead.uerj.br/VICBG-2004/Eixo1/e1_contsn4.htm.

Disponível

Questão Agrária: conflitualidade e desenvolvimento territorial. 2004d. http://www.reformaagrariaemdados.org.br/sites/default/files/FERNANDES\%202004\%20ques $\mathrm{t} \% \mathrm{C} 3 \% \mathrm{~A} 3 \mathrm{o} \% 20 \mathrm{agr} \% \mathrm{C} 3 \% \mathrm{~A} 1$ ria $\% 20$ conflitualidade $\% 20 \mathrm{e} \% 20$ desenvolvimento $\% 20$ territorial. pdf. Acesso em: 15 jul. 2019d.

FREIRE, P. A Pedagogia do oprimido. Paz e Terra, Rio de Janeiro, 1987

MAPA - Ministério da Agricultura, Pecuária e do Abastecimento. O Plano Safra 2020/21. Brasília. 2021.

MARTINS. J. de S. A modernidade do "passado" no meio rural. O mundo rural no Brasil do século 21: a formação de um novo padrão agrário e agrícola. In: BUAINAIN, A. M. ALVES, E., SILVEIRA, J. M da, NAVARRO, Z. editores técnicos. - Brasília, DF: Embrapa, 2014. 1182 p.: il. Color. $18,5 \mathrm{~cm}$ por $25,5 \mathrm{~cm}$. 
OLIVEIRA, A. U. de. Educação e ensino de geografia na realidade brasileira. In: OLIVEIRA, A. U. de (Org.). Para onde vai o ensino da geografia? 4. ed. São Paulo: Pinski, 1994.

PORTELA, F; FERNANDES, B. M. Reforma agrária. São Paulo: Ática, 2004d.

QUEIROZ, F. A. de. Impactos da sojicultura de exportação sobre a biodiversidade do cerrado. Sociedade \& Natureza, Uberlândia, 21 (2): 193-209, ago. 2009. Disponível em: https://www.scielo.br/pdf/sn/v21n2/a13v21n2.pdf. Acesso em: 22 maio 2020.

SCHNEIDER, S. Teoria social, agricultura familiar e pluriatividade. Revista Brasileira de Ciências Sociais 18(51). 2003.

SNYDERS, G. Escola, Classes e Luta de Classes. São Paulo: Centauro, 2005.

SUZUKI, J.C. Geografia agrária: gênese e diversidade. In: MARAFON, G J; RUA, J; RIBEIRO, M. Â. (Org.). Abordagens teórico-metodológicas em geografia agrária. Rio de Janeiro: Eduerj, 2007.

TORREZANI, N. Vontade de Saber geografia. $6^{\circ}$. São Paulo: FTD, $2015 \mathrm{a}$.

Vontade de Saber geografia. $6^{\circ}$. São Paulo: FTD, 2015b.

VESENTINI, J. W. Para uma geografia crítica na escola: textos críticos. São Paulo: Ática, 1998.

VOLPATO, G.L. Ciência: da Filosofia a Publicação. São Paulo: Editora Cultura Acadêmica, p. 217. 2013.

WELCH, C. A, FERNANDES, B. M. Agricultura e mercado: campesinato e agronegócio da laranja nos EUA e Brasil. In: PAULINO, E. T. FABRINI, J. E. Campesinato e Territórios em Disputa. São Paulo: Editora Expressão Popular, 2008. 